\title{
Hyperthermic intrathoracic chemotherapy (HITHOC): narrative review of the current literature, recommendations and future studies
}

\author{
Till Markowiak $^{1}$, Christopher Larisch $^{1}$, Hans-Stefan Hofmann ${ }^{1,2}$, Michael Ried $^{1}$ \\ ${ }^{1}$ Department of Thoracic Surgery, University Medical Center Regensburg, Regensburg, Germany; ${ }^{2}$ Department of Thoracic Surgery, Hospital \\ Barmherzige Brüder Regensburg, Regensburg, Germany \\ Contributions: (I) Conception and design: All authors; (II) Administrative support: T Markowiak, M Ried; (III) Provision of study materials or \\ patients: None; (IV) Collection and assembly of data: None; (V) Data analysis and interpretation: None; (VI) Manuscript writing: All authors; (VII) \\ Final approval of manuscript: All authors. \\ Correspondence to: Prof. Dr. Michael Ried. Department of Thoracic Surgery, University Medical Center Regensburg, Franz-Josef-Strauß-Allee 11, \\ D-93053 Regensburg, Germany. Email: michael.ried@ukr.de.
}

\begin{abstract}
Although the method of hyperthermic intrathoracic chemotherapy (HITHOC) after cytoreductive surgery is known for more than 20 years now, the interest of the scientific community has been growing especially in recent years with annually increasing numbers of publications. The feasibility and safety of HITHOC has already been demonstrated. The primary objective now is to reach a consent about the optimal implementation and standardization of the procedure. In the international clinical practice of HITHOC the parameters of temperature, duration, type and number of chemotherapeutic agents vary, making a comparison of the short- and long-term results difficult. For about ten years, the combination of surgical cytoreduction and HITHOC has been performed more routinely in several departments of thoracic surgery in Germany, especially in university hospitals. Recently, a group of experts for thoracic surgery of five departments of thoracic surgery elaborated recommendations for the HITHOC procedure in Germany. These recommendations represent a standardized and consistent implementation of HITHOC. Through this, postoperative complications associated to HITHOC should be reduced and a better comparison of the results should be enabled. This article is intended to give a brief overview of the literature, current recommendations in the implementation of HITHOC and also aims to show future perspectives of this procedure.
\end{abstract}

Keywords: Hyperthermic intrathoracic chemotherapy (HITHOC); malignant pleural mesothelioma (MPM); thymoma; thymic carcinoma; multimodality treatment

Submitted Jul 21, 2020. Accepted for publication Feb 05, 2021.

doi: 10.21037/atm-20-5444

View this article at: http://dx.doi.org/10.21037/atm-20-5444

\section{Introduction}

The method of hyperthermic intrathoracic chemotherapy (HITHOC) for the treatment of primary or secondary pleural tumors has been known for several years already. Recently, however, the scientific interest in this procedure has increased. This article is intended to give a brief overview of the literature, current recommendations in the implementation of HITHOC and also aims to show future perspectives of this procedure.

We present the following article in accordance with the Narrative Review reporting checklist (available at http://

^ ORCID: 0000-0002-5364-6206. 


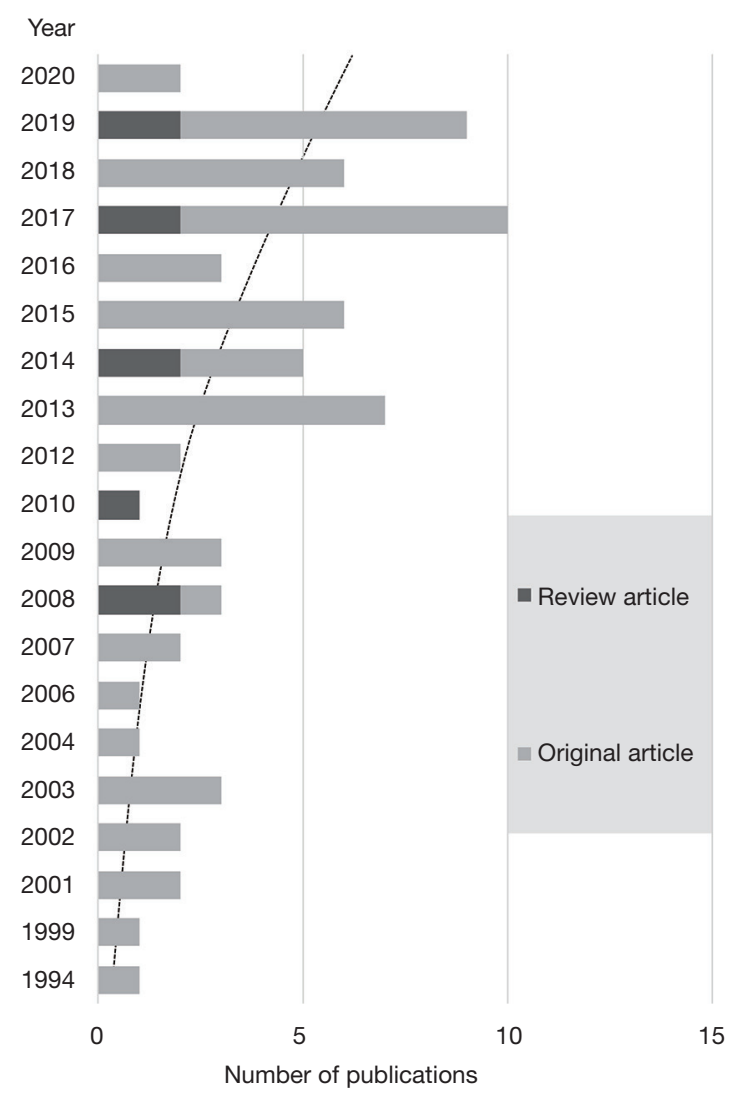

Figure 1 Development of HITHOC-related publications (70 in total). HITHOC, hyperthermic intrathoracic chemotherapy.

dx.doi.org/10.21037/atm-20-5444).

\section{Review of the current literature}

\section{Literature research}

To identify HITHOC-associated literature we conducted a search using the term "hyperthermic intrathoracic chemotherapy" and its synonyms (e.g., "hyperthermic intrathoracic chemoperfusion", "hyperthermic pleural perfusion", HITHOC, HITOC) in PubMed. This resulted in a total of 189 entries. From this and other sources 70 HITHOC-associated publications were identified (date: 20.05.2020), of which 61 articles were original papers and nine were reviews. Figure 1 shows an overview of the development in the number of HITHOC-related publications over the last two decades, demonstrating a growing scientific interest in the procedure. We present the following article in accordance with the Narrative Review
Markowiak et al. HITHOC: current literature and future perspectives

reporting checklist.

\section{Basic research}

There is only little bench research that investigates the fundamentals of HITHOC. Additionally, these studies have examined almost solely the effect on malignant pleural mesothelioma (MPM) cells. Already in 2008 Matsuzaki et al. demonstrated that the combination of intrapleural cisplatin and hyperthermia $\left[200 \mathrm{mg} / \mathrm{m}^{2}\right.$ body surface area (BSA), 120 minutes, $43^{\circ} \mathrm{C}$ ] induces potent apoptosis of tumor cells in patients with MPM, increasing immediately after perfusion and peaking at 24 hours postoperatively (1). The known mechanisms of cisplatin in this context are mitochondrial depolarization, phosphatidylserine translocation and caspase activation (2). That the induction of apoptosis thereby is dependent on the concentration of cisplatin could be demonstrated on human MPM cell lines JU77, LO68 and ONE58 by Cregan et al. and on NCI-H28, NCI-H2052, and MSTO-211H by Cameron and colleagues. Both concluded that higher doses of cisplatin result in smaller percentages of viable tumor cells $(2,3)$.

Hyperthermia offers synergistic antineoplastic effects, but the effect of hyperthermia alone on mesothelioma cells in temperatures up to $42{ }^{\circ} \mathrm{C}$ proved to be small in an in-vitro evaluation, considerably better only in temperatures higher than $45^{\circ} \mathrm{C}(1,4,5)$. However, it seems to increase local drug absorption and cytotoxic effect of cisplatin also in lower temperatures, especially when combined with a second cytostatic agent $(3,6)$. One possible explanation for this may be a hyperthermia-induced reduction of chemotherapy resistance of the malignant cells (7).

The major advantage of HITHOC is the high local and the low systemic concentration of the chemotherapeutic agents. The identified dose response relationship emphasizes the role of the local cytostatic drug concentration in the lung tissue, which also has already been the subject of previous research. A lavage of cisplatin in a concentration of $0.05 \mathrm{mg} / \mathrm{mL}$ over 60 minutes at $42{ }^{\circ} \mathrm{C}$ is known to result in tissue concentrations of $2.4 \mu \mathrm{g} / \mathrm{mL}$ (1 mm depth), $1.4 \mu \mathrm{g} / \mathrm{mL}$ (2 mm depth) and $0.5 \mu \mathrm{g} / \mathrm{mL}$ (4 mm depth) in ex-vivo conditions. A median penetration depth of 3-4 $\mathrm{mm}$ of cisplatin also appears promising, considering that the thick parts of the tumor are surgically removed (macroscopic complete resection) before perfusion and only residual, superficial cells are the target of this additional treatment (5). Low absorption through the tissue after pleurectomy/decortication (P/D) is required and 
Table 1 Overview of studies reporting on HITHOC in patients with MPM

\begin{tabular}{|c|c|c|c|c|c|}
\hline Author, year & $\begin{array}{l}\text { Cases of } \\
\operatorname{MPM}(\mathrm{n})\end{array}$ & Surgery (n) & $\begin{array}{l}\text { HITHOC: chemotherapeutics; time of perfusion; } \\
\text { temperature }\end{array}$ & $\begin{array}{l}\text { Morbidity } \\
\text { (\%) }\end{array}$ & $\begin{array}{l}\text { Mortality } \\
(\%)\end{array}$ \\
\hline Rusch et al., 1994 (9) & 28 & P/D: 28 & $\begin{array}{l}\text { Cisplatin }\left(75-100 \mathrm{mg} / \mathrm{m}^{2}\right) \text {, mitomycin }\left(8 \mathrm{mg} / \mathrm{m}^{2}\right) \text {; } \\
60 \mathrm{~min} \text {; no heating }\end{array}$ & 20 & 0 \\
\hline Ratto et al., 1999 (4) & 10 & P/D: 3; EPP: 4 & Cisplatin $\left(100 \mathrm{mg} / \mathrm{m}^{2}\right) ; 60 \mathrm{~min} ; 41.5^{\circ} \mathrm{C}$ & NA & 0 \\
\hline Yellin et al., 2001 (10) & 7 & $\begin{array}{l}\text { P/D: } 1 ; \\
\text { exploration: } 2 \text {; } \\
\text { EPP: } 4\end{array}$ & Cisplatin $\left(150-200 \mathrm{mg} / \mathrm{m}^{2}\right) ; 60 \mathrm{~min} ; 42{ }^{\circ} \mathrm{C}$ & 42.9 & 14.3 \\
\hline De Bree et al., 2002 (11) & 11 & P/D: 7; EPP: 4 & $\begin{array}{l}\text { Cisplatin }\left(80 \mathrm{mg} / \mathrm{m}^{2}\right)+\text { doxorubicin }\left(20-30 \mathrm{mg} / \mathrm{m}^{2}\right) \\
90 \mathrm{~min} ; 40-41^{\circ} \mathrm{C}\end{array}$ & 47 & 0 \\
\hline Van Ruth et al., 2003 (12) & 20 & P/D: 12; EPP: 8 & $\begin{array}{l}\text { Cisplatin }\left(80 \mathrm{mg} / \mathrm{m}^{2}\right)+\text { doxorubicin }\left(>20 \mathrm{mg} / \mathrm{m}^{2}\right) \text {; } \\
90 \mathrm{~min} ; 40-41^{\circ} \mathrm{C}\end{array}$ & 65 & 0 \\
\hline Zellos et al., 2009 (15) & 29 & EPP: 29 & Cisplatin $\left(75-200 \mathrm{mg} / \mathrm{m}^{2}\right)$ & NA & 7 \\
\hline Tilleman et al., 2009 (16) & 92 & EPP: 92 & Cisplatin $\left(225 \mathrm{mg} / \mathrm{m}^{2}\right)$ & 49 & 4.3 \\
\hline Ried et al., 2013 (17) & 8 & P/D: 8 & Cisplatin $\left(100-150 \mathrm{mg} / \mathrm{m}^{2}\right) ; 60 \mathrm{~min} ; 42{ }^{\circ} \mathrm{C}$ & 13 & 0 \\
\hline Sugarbaker et al., 2013 (18) & 72 & $\begin{array}{l}\text { P/D: } 19 \\
\text { EPP: } 53\end{array}$ & Cisplatin $\left(175-225 \mathrm{mg} / \mathrm{m}^{2}\right) ; 60 \mathrm{~min} ; 42^{\circ} \mathrm{C}$ & NA & $\begin{array}{c}4 \text { (HITHOC- } \\
\text { associated: } \\
0 \%)\end{array}$ \\
\hline Migliore et al., 2015 (19) & 6 & P/D: 6 & Cisplatin $\left(120 \mathrm{mg} / \mathrm{m}^{2}\right) ; 60 \mathrm{~min} ; 42.5^{\circ} \mathrm{C}$ & 16.6 & 0 \\
\hline Ishibashi et al., 2015 (20) & 4 & P/D: 4 & Cisplatin $\left(80 \mathrm{mg} / \mathrm{m}^{2}\right) ; 60 \mathrm{~min} ; 42{ }^{\circ} \mathrm{C}$ & 100 & 0 \\
\hline Bertoglio et al., 2017 (21) & 26 & P/D: 26 & Cisplatin $\left(80 \mathrm{mg} / \mathrm{m}^{2}\right)+$ doxorubicin $\left(25 \mathrm{mg} / \mathrm{m}^{2}\right)$ & 30 & 0 \\
\hline Klotz et al., 2019 (25) & 71 & P/D: 71 & Cisplatin $(200 \mathrm{mg})+$ doxorubicin $(100 \mathrm{mg}) ; 90 \mathrm{~min} ; 42{ }^{\circ} \mathrm{C}$ & 57.7 & 1.4 \\
\hline
\end{tabular}

EPP, extrapleural pneumonectomy; HITHOC, hyperthermic intrathoracic chemotherapy; NA, data not available; P/D, pleurectomy/decortication.

proven even when applying high doses to avoid typical side effects of systemic cisplatin such as renal insufficiency (8). In serum samples the bioavailability of intrapleurally administered cisplatin reached only a fraction of about $2 \%$ with a peak 60 minutes after HITHOC (8).

\section{Clinical data}

Tables 1,2 show clinical studies of the two major indications for HITHOC: MPM and pleurally disseminated thymic tumors in Masaoka-Koga stage IVA. The majority of these publications are observational, retrospectively designed phase I-II studies. Not only that the numbers of observed patients in these (especially in the case of thymic tumors) rare diseases are low. In clinical practice the parameters of temperature, duration, type and number of chemotherapeutic agents vary, making a comparison of the short- and long-term results difficult.

A common feature of all studies is the administration of cisplatin in dosages between 50 and $225 \mathrm{mg} / \mathrm{m}^{2}$ BSA $(11,16)$. 
Table 2 Overview of studies reporting on HITHOC in patients with thymic tumor

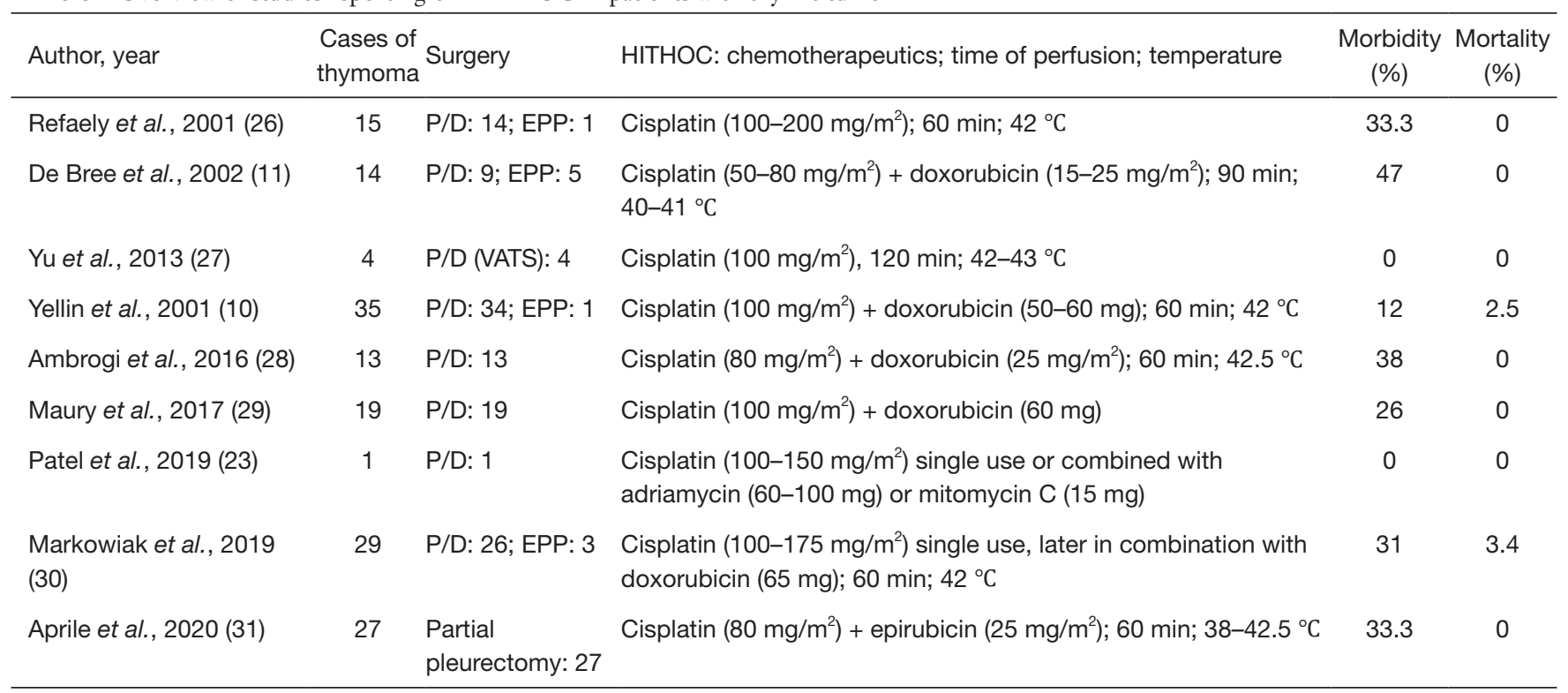

EPP, extrapleural pneumonectomy; HITHOC, hyperthermic intrathoracic chemotherapy; P/D, pleurectomy/decortication; VATS, video-assisted thoracoscopic surgery.

Important steps towards a safe performance of HITHOC were the identification of the maximum-tolerable cisplatin dosage of $225 \mathrm{mg} / \mathrm{m}^{2}$ BSA by Richards et al. and the implementation of a nephroprotective regime consisting of amifostine, sodium thiosulfate and forced diuresis $(13,32)$. Higher intrathoracic concentrations of cisplatin lead to increased rates of systemic side effects, especially regarding postoperative renal insufficiency (13). The application below this threshold demonstrated to be safe. Cisplatin is frequently used alone, but sometimes also in combination with doxorubicin, mitomycin, epirubicin, adriamycin or gemcitabine (Table 1). Both the therapeutic benefit and the optimal dosage of the second cytostatic drug remain unclear in the clinical setting. In a phase I study by Burt et al., a maximum tolerable gemcitabine dose of $1,000 \mathrm{mg} / \mathrm{m}^{2}$ BSA was determined when combined with cisplatin (24).

Thus, growing clinical expertise in perioperative management contributed to a reduction of severe perioperative complications. In addition to renal insufficiency, thromboembolic events are particularly to be mentioned in the postoperative period. Since the case numbers are small, the range of reported morbidity and mortality is wide. However, perioperative mortality in particular is low or moderate in the studies with more than 40 patients at rates of $0-11 \%(13,16,18,22,24,25)$. Furthermore, postoperative morbidity and mortality are mainly caused by the surgical cytoreduction itself and not primarily by the subsequent HITHOC. The International Mesothelioma Interest Group (IMIG) in 2012 and available international guidelines recommend lung-sparing techniques like $\mathrm{P} / \mathrm{D}$ or extended pleurectomy/decortication $(\mathrm{eP} / \mathrm{D})$ instead of extrapleural pneumonectomy (EPP) in order to reduce the risk of postoperative complications (33-35). The 2020 published guideline of the European Respiratory Society (ERS), European Society of Thoracic Surgeons (ESTS), European Association for CardioThoracic Surgery (EACTS) and the European Society for Radiotherapy and Oncology (ESTRO) for the management of MPM does not address intracavitary local therapies. According to the authors, HITHOC should at least be mentioned as a potential therapy option (36). However, additional local procedures (e.g., intracavitary chemotherapy) are still under investigation and can be performed within a multimodality treatment regime in experienced centers along to study protocols (35).

Similar to basic research, the best clinical data is available in patients with MPM. With our structured search we were able to identify 21 studies that investigated HITHOC on this tumor entity, 18 of them are displayed in Table 1 (e.g., because some were not available in English or German language). The cohorts range from case series with four patients to a maximum of 104 patients $(20,24)$. The survival 
of MPM patients after multimodal therapy including HITHOC lies between 11 and 36 months in the literature $(12,21)$. A significant advantage in in extending median survival was demonstrated by Sugarbaker et al. (18) in a retrospective study with 103 participants (surgery only: 22.8 months vs. surgery + HITHOC: 35.3 months; $\mathrm{P}=0.026$ ).

With regard to thymic tumors, as the second leading indication for HITHOC, we identified 14 clinical studies, 12 are displayed in Table 2. With 35 patients the largest cohort with this entity was described by Yellin et al. and to our best knowledge only three studies with more than 20 patients exist $(30,31,37)$. With treatment concepts including only surgery and radiochemotherapy reported 5 -year survival rates are between $53 \%$ and $88 \%(38,39)$. When combined with HITHOC, 5 -year survival rates of $80-92 \%$ were demonstrated $(26,28,30,37)$. Survival in these studies has depended especially on tumor histology since thymic carcinoma showed a considerably worse survival and therefore should be treated and reported as a separate entity $(30,37)$. The indolent nature of histological subtypes $\mathrm{A}, \mathrm{AB}$ and $\mathrm{B} 1-3$, in turn, makes it certainly difficult to verify an advantage in survival by the application of HITHOC. However, Aprile et al. reported a benefit in median diseasefree survival comparing surgery alone with combined surgery and HITHOC retrospectively (surgery + HITHOC: $88.0 \pm 15$ months vs. surgery only: $57 \pm 19.5$ months; $\mathrm{P}=0.046$ ) (31). In contrast to MPM, clinical practice guidelines of this tumor entity already mention HITHOC as a therapeutic option in pleural manifestations (40).

Only few authors reported about the use in patients with secondary pleural carcinosis and malignant pleural effusion. A future potential of HITHOC might lie in secondary pleural carcinosis in patients with lung cancer stage IVA, which is the most common cause of malignant pleural effusion with about $40 \%$ (41). Although reported survival is promising, the recent data on this approach is weak and needs further investigation as shown in a systematic review by Migliore et al. (42).

\section{Recommendations}

Since approximately 10 years surgical cytoreduction in combination with HITHOC is performed more routinely in several departments for thoracic surgery in Germany, especially in University Hospitals. First experiences have been presented as retrospective studies in meetings and publications $(17,25,30,32,43)$. Based on research data and clinical experiences, the next step was to generate the first expert recommendation in order to develop elementary recommendations for a standardized HITHOC protocol (44). Therefore, a group of experts for thoracic surgery of five departments of thoracic surgery (Regensburg, Munich, Heidelberg, Freiburg, Cologne) elaborated recommendations for the HITHOC procedure in Germany. All recommendations were based on clinical experiences, research data of the experts and the recent literature. Finally, a total of six main emphases including a total of 17 recommendations were developed of which the most important ones are listed in Table 3. A 100\% agreement was reached for the nomenclature, the technique, the chemotherapeutic agent, the perioperative management, the safety measures and the indications for HITHOC.

Indications for cytoreductive surgery $(\mathrm{P} / \mathrm{D}, \mathrm{eP} / \mathrm{D}$ or EPP) combined with HITHOC meet the same criteria as described in the international literature: MPM, thymic tumors with pleural spread and selected patients with secondary pleural carcinosis. The HITHOC should always be performed after surgical cytoreduction. Without prior surgical tumor removal, only palliative perfusion of the pleural space in palliative intention and subsequent pleurodesis is achievable. In addition, the HITHOC should be implemented in the same surgery rather in exceptional cases in a second operation. Before starting the HITHOC, the thoracic incisions should be closed after placing the inflow and outflow drainages correctly in the thoracic cavity (Figure 2). According to the available literature, the HITHOC runs for 60 minutes and at approximately $42{ }^{\circ} \mathrm{C}$ in the system or drainages. The temperature should be monitored during HITHOC inside the pleural space with appropriate dedicated intrathoracic sensors.

Cisplatin was recommended as the first-choice chemotherapeutic agent for HITHOC and therefore cisplatin should always play the major role for the chemotherapeutic perfusion. The dosage of cisplatin should be specified in $\mathrm{mg} / \mathrm{m}^{2}$ BSA and given in a dosage between $150-175 \mathrm{mg} / \mathrm{m}^{2}$ BSA. The volume of the perfusion fluid seems to play a role for the concentration gradient of cisplatin in the pleural space during circulation and should be taken into account. Both, the dosage of cisplatin and the amount of perfusion fluid, are essential to establish a high intrathoracic concentration of cisplatin, which hopefully improves control of the local residual microscopic tumor disease. The volume of the perfusion fluid can either be determined clinically (addition until a stable circulation is established) or calculated in relation to the BSA (for example $2.5 \times$ BSA in liters). During 
Table 3 Recommendations for HITHOC according to Ried et al. (44)

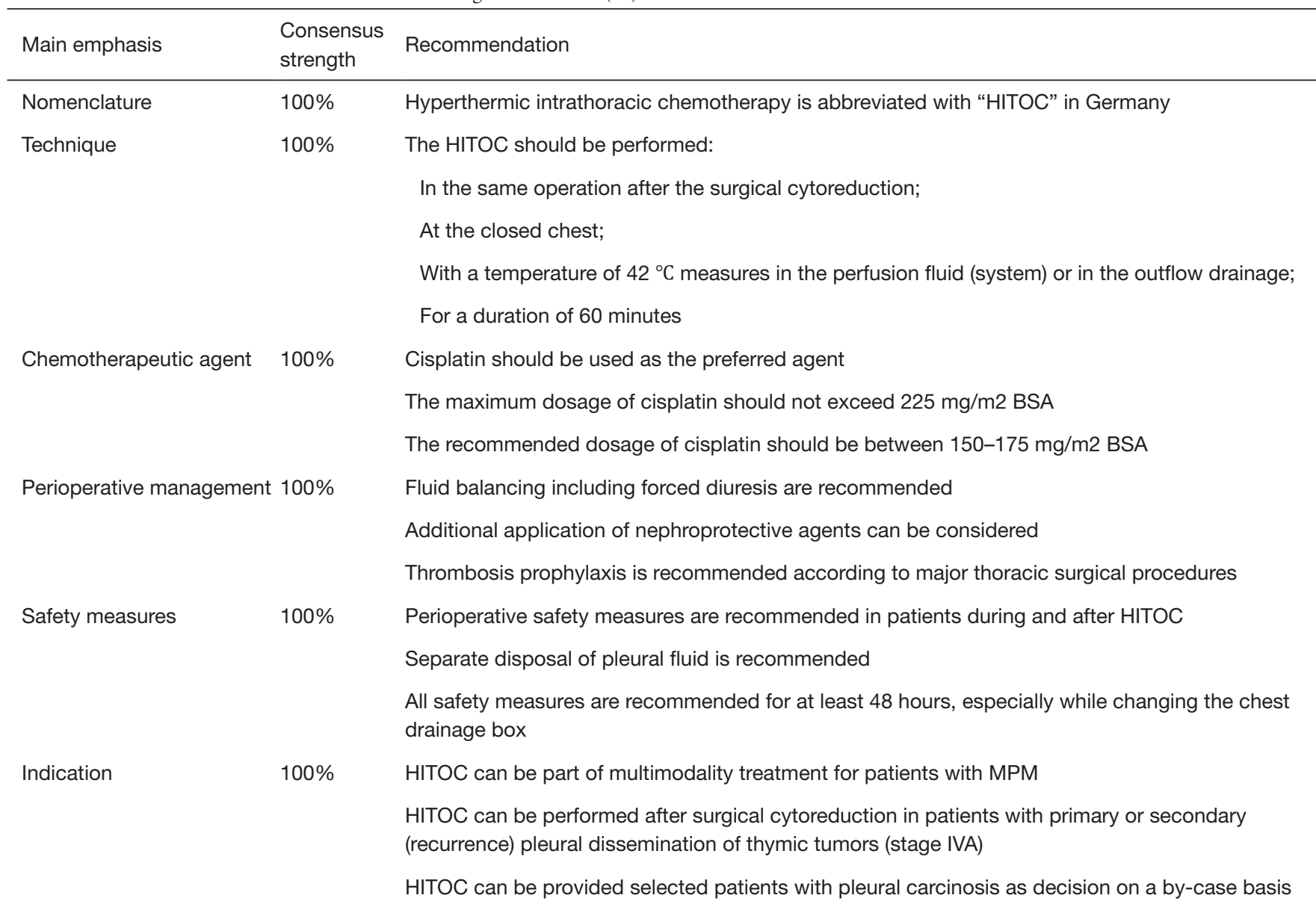

HITHOC, hyperthermic intrathoracic chemotherapy; BSA, body surface area; MPM, malignant pleural mesothelioma.

the perioperative period, fluid balancing is recommended in order to reduce renal complications. In addition, nephroprotective agents can be considered (32). Certain intra- and postoperative safety measures for the involved personal should be strictly performed for the first 48 hours after HITHOC: special protective clothing including safety glasses and enhanced surgical gloves as well as separated disposal of the pleural fluid.

These expert recommendations represent a standardized and consistent implementation of the HITHOC procedure in Germany (44). Through this, postoperative complications associated to HITHOC should be reduced and a better comparison of the results should be enabled.

\section{Future studies}

Innovative procedures like the HITHOC run through an interminable process as illustrated in Figure 3. First case reports/series and retrospective studies with small sample sizes investigated the feasibility and safety of the procedure. As mentioned above, the indication of only rare tumor entities and the various techniques of HITHOC as well as cytotoxic agents with varying dosages made it difficult to compare the few available studies in the international literature. However, the next step after approving the safety of the procedure was to standardize the HITHOC as far as possible.

Currently, a retrospective, multi-center observational study, which is funded by the German Research Foundation analyses approximately 350 patients who underwent surgical cytoreduction combined with subsequent HITHOC in four German University Hospitals (46). The results of this retrospective, multi-center study should allow a better standardization of the HITHOC-procedure including 


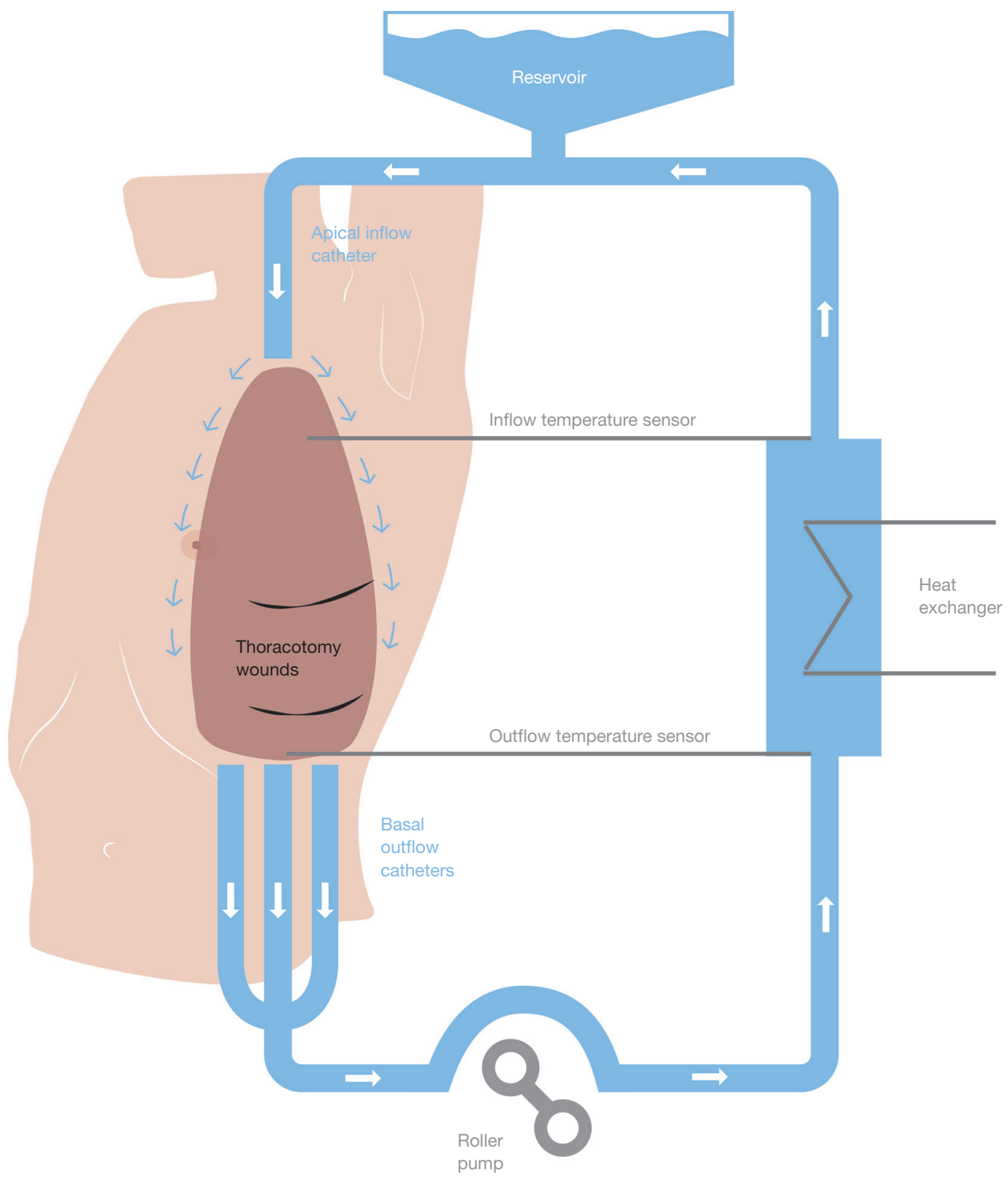

Figure 2 Schematic setup of a HITHOC: the apical inflow drainage reaches up to the costodiaphragmatic recess, the three basal outflow drains are placed ventral, interlobar and dorsal (45). HITHOC, hyperthermic intrathoracic chemotherapy.

perioperative safety measures in Germany and also validate the existing clinical experience. First results are expected at the beginning of the next year and further analysis regarding survival rates are right from the planning stage.

But also prospective studies with special emphasis of multimodality protocols including HITHOC and innovative adjuvant chemotherapy are strongly required.
One interventional, randomized clinical trial is currently performed in Germany (ClinicalTrials.gov Identifier: NCT04177953), which is called NICITA: Nivolumab with Chemotherapy in Pleural Mesothelioma After Surgery. This multicenter, randomized, controlled, open-label study includes patients with MPM in tumor stages I-III who have previously undergone cytoreductive surgery by $\mathrm{eP} /$ 


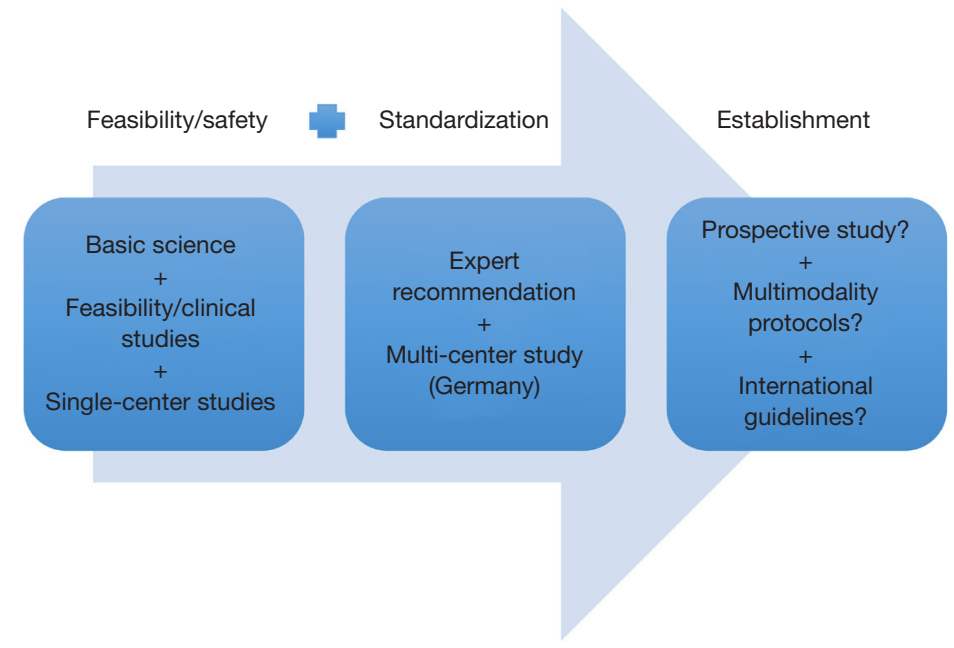

Figure 3 Process of innovative procedures like the HITHOC. HITHOC, hyperthermic intrathoracic chemotherapy.

D with or without HITHOC. After surgery, the patients will receive a maximum treatment duration of 16 cycles: 4 cycles of platinum-based chemotherapy in both arms +12 cycles maintenance immunotherapy with nivolumab in the treatment arm. The main objective of the trial is time-tonext-treatment (TNT), as well as safety and tolerability (47).

Although the mentioned ongoing studies will hopefully provide valid data for a more standardized multimodality therapy concept, additional clinical studies are warranted for the future. These results are crucial in order to include the HITHOC into future international guidelines for the treatment of MPM and thymoma with pleural spread or even secondary pleural carcinosis.

\section{Conclusions}

The number of published HITHOC-related papers increases annually, demonstrating a growing interest of the scientific community in the procedure. According to the available literature, cytoreductive surgery combined with HITHOC can be considered in patients with MPM, thymic tumors with pleural spread and selected patients with secondary pleural carcinosis. The feasibility has been demonstrated in several studies and growing clinical expertise in perioperative management and technique led to tolerably lower rates of complications. First resulting survival data are encouraging and give rationale for further investigations. The results of ongoing clinical studies are expected soon and are necessary to hopefully include HITHOC into international guidelines. A standardization of the procedure will ensure comparability of short- and long-term results in the future.

\section{Acknowledgments}

Funding: None.

\section{Footnote}

Provenance and Peer Review: This article was commissioned by the Guest Editor (Marcello Migliore) for the series "Hyperthermic Intraoperative Chemotherapy (HITHOC) in thoracic surgical oncology" published in Annals of Translational Medicine. The article has undergone external peer review.

Reporting Checklist: The authors have completed the Narrative Review reporting checklist. Available at http:// dx.doi.org/10.21037/atm-20-5444

Conflicts of Interest: All authors have completed the ICMJE uniform disclosure form (available at http://dx.doi. org/10.21037/atm-20-5444). The series "Hyperthermic Intraoperative Chemotherapy (HITHOC) in thoracic surgical oncology" was commissioned by the editorial office without any funding or sponsorship. The authors have no other conflicts of interest to declare.

Ethical Statement: The authors are accountable for all aspects of the work in ensuring that questions related 
to the accuracy or integrity of any part of the work are appropriately investigated and resolved.

Open Access Statement: This is an Open Access article distributed in accordance with the Creative Commons Attribution-NonCommercial-NoDerivs 4.0 International License (CC BY-NC-ND 4.0), which permits the noncommercial replication and distribution of the article with the strict proviso that no changes or edits are made and the original work is properly cited (including links to both the formal publication through the relevant DOI and the license). See: https://creativecommons.org/licenses/by-nc-nd/4.0/.

\section{References}

1. Matsuzaki Y, Tomita M, Shimizu T, et al. Induction of apoptosis by intrapleural perfusion hyperthermochemotherapy for malignant pleural mesothelioma. Ann Thorac Cardiovasc Surg 2008;14:161-5.

2. Cregan IL, Dharmarajan AM, Fox SA. Mechanisms of cisplatin-induced cell death in malignant mesothelioma cells: role of inhibitor of apoptosis proteins (IAPs) and caspases. Int J Oncol 2013;42:444-52.

3. Cameron RB, Hou D. Intraoperative hyperthermic chemotherapy perfusion for malignant pleural mesothelioma: an in vitro evaluation. J Thorac Cardiovasc Surg 2013;145:496-504.

4. Ratto GB, Civalleri D, Esposito M, et al. Pleural space perfusion with cisplatin in the multimodality treatment of malignant mesothelioma: a feasibility and pharmacokinetic study. J Thorac Cardiovasc Surg 1999;117:759-65.

5. Ried M, Lehle K, Neu R, et al. Assessment of cisplatin concentration and depth of penetration in human lung tissue after hyperthermic exposure. Eur J Cardiothorac Surg 2015;47:563-6.

6. Mujoomdar AA, Sugarbaker DJ. Hyperthermic chemoperfusion for the treatment of malignant pleural mesothelioma. Semin Thorac Cardiovasc Surg 2008;20:298-304.

7. Christophi C, Winkworth A, Muralihdaran V, et al. The treatment of malignancy by hyperthermia. Surg Oncol 1998;7:83-90.

8. Ried M, Potzger T, Braune N, et al. Local and systemic exposure of cisplatin during hyperthermic intrathoracic chemotherapy perfusion after pleurectomy and decortication for treatment of pleural malignancies. J Surg Oncol 2013;107:735-40.

9. Rusch V, Saltz L, Venkatraman E, et al. A phase II trial of pleurectomy/decortication followed by intrapleural and systemic chemotherapy for malignant pleural mesothelioma. J Clin Oncol 1994;12:1156-63.

10. Yellin A, Simansky DA, Paley M, et al. Hyperthermic pleural perfusion with cisplatin: early clinical experience. Cancer 2001;92:2197-203.

11. de Bree E, van Ruth S, Baas P, et al. Cytoreductive surgery and intraoperative hyperthermic intrathoracic chemotherapy in patients with malignant pleural mesothelioma or pleural metastases of thymoma. Chest 2002;121:480-7.

12. van Ruth S, Baas P, Haas RL, et al. Cytoreductive surgery combined with intraoperative hyperthermic intrathoracic chemotherapy for stage I malignant pleural mesothelioma. Ann Surg Oncol 2003;10:176-82.

13. Richards WG, Zellos L, Bueno R, et al. Phase I to II study of pleurectomy/decortication and intraoperative intracavitary hyperthermic cisplatin lavage for mesothelioma. J Clin Oncol 2006;24:1561-7.

14. van Sandick JW, Kappers I, Baas P, et al. Surgical treatment in the management of malignant pleural mesothelioma: a single institution's experience. Ann Surg Oncol 2008;15:1757-64.

15. Zellos L, Richards WG, Capalbo L, et al. A phase I study of extrapleural pneumonectomy and intracavitary intraoperative hyperthermic cisplatin with amifostine cytoprotection for malignant pleural mesothelioma. J Thorac Cardiovasc Surg 2009;137:453-8.

16. Tilleman TR, Richards WG, Zellos L, et al. Extrapleural pneumonectomy followed by intracavitary intraoperative hyperthermic cisplatin with pharmacologic cytoprotection for treatment of malignant pleural mesothelioma: a phase II prospective study. J Thorac Cardiovasc Surg 2009;138:405-11.

17. Ried M, Potzger T, Braune N, et al. Cytoreductive surgery and hyperthermic intrathoracic chemotherapy perfusion for malignant pleural tumours: perioperative management and clinical experience. Eur J Cardiothorac Surg 2013;43:801-7.

18. Sugarbaker DJ, Gill RR, Yeap BY, et al. Hyperthermic intraoperative pleural cisplatin chemotherapy extends interval to recurrence and survival among low-risk patients with malignant pleural mesothelioma undergoing surgical macroscopic complete resection. J Thorac Cardiovasc Surg 2013;145:955-63.

19. Migliore M, Calvo D, Criscione A, et al. Cytoreductive surgery and hyperthermic intrapleural chemotherapy for malignant pleural diseases: preliminary experience. Future 
Oncol 2015;11:47-52.

20. Ishibashi $H$, Kobayashi $M$, Takasaki C, et al. Interim results of pleurectomy/decortication and intraoperative intrapleural hyperthermic cisplatin perfusion for patients with malignant pleural mesothelioma intolerable to extrapleural pneumonectomy. Gen Thorac Cardiovasc Surg 2015;63:395-400.

21. Bertoglio P, Ambrogi MC, Chella A, et al. Is less also better? A single-institution experience on treatment of early stage Malignant Pleural Mesothelioma. Eur J Surg Oncol 2017;43:1365-71.

22. Ambrogi MC, Bertoglio P, Aprile V, et al. Diaphragm and lung-preserving surgery with hyperthermic chemotherapy for malignant pleural mesothelioma: A 10-year experience. J Thorac Cardiovasc Surg 2018;155:1857-1866.e2.

23. Patel MD, Damodaran D, Rangole A, et al. Hyperthermic Intrathoracic Chemotherapy (HITHOC) for Pleural Malignancies-Experience from Indian Centers. Indian J Surg Oncol 2019;10:91-8.

24. Burt BM, Richards WG, Lee HS, et al. A Phase I Trial of Surgical Resection and Intraoperative Hyperthermic Cisplatin and Gemcitabine for Pleural Mesothelioma. J Thorac Oncol 2018;13:1400-9.

25. Klotz LV, Lindner M, Eichhorn ME, et al. Pleurectomy/ decortication and hyperthermic intrathoracic chemoperfusion using cisplatin and doxorubicin for malignant pleural mesothelioma. J Thorac Dis 2019;11:1963-72.

26. Refaely Y, Simansky DA, Paley M, et al. Resection and perfusion thermochemotherapy: a new approach for the treatment of thymic malignancies with pleural spread. Ann Thorac Surg 2001;72:366-70.

27. Yu L, Jing Y, Ma S, et al. Cytoreductive surgery combined with hyperthermic intrapleural chemotherapy to treat thymoma or thymic carcinoma with pleural dissemination. Onco Targets Ther 2013;6:517-21.

28. Ambrogi MC, Korasidis S, Lucchi M, et al. Pleural recurrence of thymoma: surgical resection followed by hyperthermic intrathoracic perfusion chemotherapydagger. Eur J Cardiothorac Surg 2016;49:321-6.

29. Maury JM, Girard N, Tabutin M, et al. Intra-Thoracic Chemo-Hyperthermia for pleural recurrence of thymoma. Lung Cancer 2017;108:1-6.

30. Markowiak T, Neu R, Ansari MKA, et al. Surgical Cytoreduction and HITOC for Thymic Malignancies with Pleural Dissemination. Thorac Cardiovasc Surg 2021;69:157-64.

31. Aprile V, Bacchin D, Korasidis S, et al. Surgical treatment of pleural recurrence of thymoma: is hyperthermic intrathoracic chemotherapy worthwhile?. Interact Cardiovasc Thorac Surg 2020;30:765-72.

32. Markowiak T, Kerner N, Neu R, et al. Adequate nephroprotection reduces renal complications after hyperthermic intrathoracic chemotherapy. J Surg Oncol 2019;120:1220-6.

33. Rusch V, Baldini EH, Bueno R, et al. The role of surgical cytoreduction in the treatment of malignant pleural mesothelioma: meeting summary of the International Mesothelioma Interest Group Congress, September 11-14, 2012, Boston, Mass. J Thorac Cardiovasc Surg 2013;145:909-10.

34. Woolhouse I, Bishop L, Darlison L, et al. BTS guideline for the investigation and management of malignant pleural mesothelioma. BMJ Open Respir Res 2018;5:e00266.

35. NCCN Clinical Practice Guidelines in Oncology (NCCN Guidelines( ${ }^{\circledR}$ ). Malignant Pleural Mesothelioma. Version 2.2019-April 1, 2019. Available online: https://www.nccn. org/professionals/physician_gls/pdf/mpm.pdf

36. Scherpereel A, Opitz I, Berghmans T, et al. ERS/ ESTS/EACTS/ESTRO guidelines for the management of malignant pleural mesothelioma. Eur Respir J 2020;55:1900953.

37. Yellin A, Simansky DA, Ben-Avi R, et al. Resection and heated pleural chemoperfusion in patients with thymic epithelial malignant disease and pleural spread: a single-institution experience. J Thorac Cardiovasc Surg 2013;145:83-7; discussion 87-9.

38. Moser B, Fadel E, Fabre D, et al. Surgical therapy of thymic tumours with pleural involvement: an ESTS Thymic Working Group Project. Eur J Cardiothorac Surg 2017;52:346-55.

39. Falkson CB, Bezjak A, Darling G, et al. The management of thymoma: a systematic review and practice guideline. $\mathrm{J}$ Thorac Oncol 2009;4:911-9.

40. Girard N, Ruffini E, Marx A, et al. Thymic epithelial tumours: ESMO Clinical Practice Guidelines for diagnosis, treatment and follow-up. Ann Oncol 2015;26 Suppl 5:v40-55.

41. Antony VB, Loddenkemper R, Astoul P, et al. Management of malignant pleural effusions. Eur Respir J 2001;18:402-19.

42. Migliore M, Nardini M. Does cytoreduction surgery and hyperthermic intrathoracic chemotherapy prolong survival in patients with N0-N1 nonsmall cell lung cancer and malignant pleural effusion? Eur Respir Rev 2019;28:190018. 
43. Ried M, Neu R, Schalke B, et al. Radical Pleurectomy and Hyperthermic Intrathoracic Chemotherapy for Treatment of Thymoma with Pleural Spread. Zentralbl Chir 2013;138 Suppl 1:S52-7.

44. Ried M, Eichhorn M, Winter H, et al. Expert

Recommendation for the Implementation of Hyperthermic Intrathoracic Chemotherapy (HITOC) in Germany. Zentralbl Chir 2020;145:89-98.

45. Markowiak T, Hofmann HS, Ried M. Intraoperative

Cite this article as: Markowiak T, Larisch C, Hofmann HS, Ried M. Hyperthermic intrathoracic chemotherapy (HITHOC): narrative review of the current literature, recommendations and future studies. Ann Transl Med 2021;9(11):955. doi: 10.21037/atm-20-5444 hypertherme intrathorakale Chemotherapie. Z HerzThorax- Gefäßchir 2019;33:15-9.

46. Markowiak T, Koller M, Zeman F, et al. Protocol of a retrospective, multicentre observational study on hyperthermic intrathoracic chemotherapy in Germany. BMJ Open 2020;10:e041511.

47. Nivolumab With Chemotherapy in Pleural Mesothelioma After Surgery. Available online: https://clinicaltrials.gov/ show/NCT04177953. Accessed 31th June 2020. 